\title{
O convívio com plantas e a boa alimentação: a atuação do design nas atividades de cultivo
}

\author{
Lia Paletta Benatti; \\ André Carvalho Mol Silva; \\ Sebastiana Luiza Bragança Lana
}

\section{resumo:}

O presente trabalho aborda a interação de crianças que habitam as residências dos ambientes urbanos nas atividades de cultivo como forma de inserir alimentos saudáveis em sua alimentação. Para isso é apresentado resultado de questionário aplicado sobre importância do cultivo e sua forma no contexto urbano, traçando-se um paralelo sobre as alternativas apresentadas pelo ponto de vista do design. Como resultado ficou entendido que o cultivo de plantas nos ambientes urbanos enfrenta uma série de dificuldades mas resiste, não como forma de trazer soberania alimentar a uma família, mas como fatores subjetivos relacionados a uma atividade terapêutica, lúdica e de conscientização ambiental. Trazendo assim, ao designer, o desafio de inserir em seus projetos fatores intangíveis que se mostram tão relevantes quanto a eficiência produtiva de uma horta doméstica.

\section{palavras-chave:}

Cultivo doméstico; plantas; design; alimentação 


\section{Introdução}

A relação das pessoas com a alimentação vem mudando nos últimos anos. Por um lado grandes empresas oferecem alimentos de forma rápida e com preços baixos, muitas vezes como redes de fastfood, comidas instantâneas, refeições congeladas, redes de delivery entre outros, que são opções práticas mas que podem perder em valor nutricional.

Os desafios do setor alimentício são diversos, mas a falta de informação e conhecimento por parte dos consumidores ainda é uma barreira a ser vencida. Não sabemos quase nada, ou muito pouco, sobre o que comemos - quem cultiva, onde e como cultiva. E, muitas vezes, nem consideramos essas informações importantes. Levado ao extremo, esse consumo que ignora as origens e as consequências de um processo produtivo é irresponsável, pois não se preocupa com os impactos negativos que todo processo pode gerar ao meio ambiente, à economia e à população, tais como poluição, degradação ambiental, pobreza, êxodo, entre tantos (PINTO, 2017, p. 385).

$\mathrm{Na}$ contramão deste estilo de alimentação, cada vez mais pessoas buscam fontes de alimentos nutritivos, saudáveis (com baixos teores de gordura e sódio) e frescos. Há uma grande valorização da produção local e dos alimentos orgânicos que não contém nenhum tipo de remédio ou agrotóxico. É possível dizer que, de certa forma, as pessoas estão reaprendendo a cozinhar e a entender os alimentos.

Desde que a erosão genética foi reconhecida internacionalmente como emergência global, as iniciativas em defesa da agrobiodiversidade e das variedades tradicionais se espalharam ao redor do mundo. Bancos de sementes, programas de proteção das variedades não convencionais, iniciativas em favor do desenvolvimento local, mapeamento e criação de base de dados das espécies fazem parte de uma estratégia adotada por uma grande variedade de atores [...] (MUGGIRI, 2017, p. 182).

Vivendo no ambiente urbano hoje temos uma série de facilidades, porém nos é restrita a escolha sobre nossa alimentação. Pelo pouco espaço das residências, como nos prédios de apartamentos, que não se localizam diretamente sobre o solo e não permitem o cultivo direto. Nos alimentamos com aquilo que nos é ofertado pela agricultura de larga escala, e temos que nos sujeitar as quantidades, preços, embalagens, entre outros fatores, que o comércio pratica.

Certamente, poucas pessoas têm a oportunidade de cultivar tudo o que consomem, porém há uma cultura, principalmente no Brasil, do cultivo de plantas quando há espaço disponível. E talvez nesta atividade tão corriqueira do brasileiro possa estar a chave para a preservação de espécies nativas, além da melhora na qualidade da alimentação.

Este contexto não é novo para o design, porém muitos dos produtos desenvolvidos consideram a eficiência do cultivo e o apelo estético como fatores predominantes, deixando de lado alguns aspectos humanos ligados à importante conexão que se dá entre pessoas e plantas, e uma série de elementos psicológicos, culturais e educativos que permeiam essa relação.

\section{Métodos}

O presente estudo tem por objetivo discorrer sobre as potencialidades do design frente as atividades de cultivo de plantas nos ambientes urbanos e relacionar estas atividades a uma alimentação saudável. A pesquisa foca especialmente na possibilidade das ações de cultivo ao longo da infância como um fator que pode possibilitar uma boa alimentação no futuro.

Acredita-se que o contato com plantas, o conhecimento sobre seu ciclo e a interação com os vegetais desde cedo podem ser fatores que auxiliam a aceitação dos alimentos naturais, em especial de legumes e verduras, pelo público infantojuvenil.

Este trabalho parte de um questionário ${ }^{1}$ formado por questões abertas e fechadas direcionado a cuidadores de crianças (pais, avós, familiares ou responsáveis) com perguntas que envolvem o cuidado

\footnotetext{
${ }^{1}$ O desenho da pesquisa foi aprovado pelo Comitê de Ética da Pesquisa da UEMG em 10 de julho de 2018.
} 
infantil e o cultivo de plantas, para posterior interpretação dos dados e apresentação das relações com a área do design.

\section{Questionário}

O questionário foi criado em plataforma online, distribuído por e-mail e divulgado em grupos de rede social ${ }^{2}$ referentes tanto ao cultivo de plantas como sobre o cuidado com crianças.

O Termo de Consentimento Livre e Esclarecido foi apresentado na primeira página do questionário, e apenas com o aceite o participante passou para as etapas de perguntas.

O objetivo foi trazer perguntas sobre o que as pessoas sabem (fatos), o que pensam, sentem, preferem (crenças e atitudes) e o que fazem (comportamento) (GIL, 2008, p. 124) em relação ao cultivo de plantas e a alimentação infantil.

\section{1 Dados dos participantes}

O questionário foi respondido por 48 pessoas, sendo 41 residentes no Brasil e 6 respostas oriundas de outros países (brasileiros residentes fora do país), que foram mantidas pela similaridade de contextos urbanos (tabela 1). A maior representatividade é oriunda do estado de Minas Gerais.

Tabela 1 - Localidade de origem dos participantes do questionário.

\begin{tabular}{|c|c|c|c|}
\hline Estado & Quantidade de participantes & País & Quantidade de participantes \\
\hline Acre & 1 & Estados Unidos & 1 \\
\hline Alagoas & 2 & Japão & 1 \\
\hline Ceará & 1 & Portugal & 2 \\
\hline Espírito Santo & 1 & Inglaterra & 1 \\
\hline Minas Gerais & 24 & & \\
\hline Pará & 1 & & \\
\hline Paraíba & 1 & & \\
\hline Paraná & 2 & & \\
\hline Rio de Janeiro & 1 & & \\
\hline Rondônia & 2 & & \\
\hline Santa Catarina & 1 & & \\
\hline São Paulo & 4 & & \\
\hline
\end{tabular}

Fonte: os autores (2018).

A maioria das respostas, 40 (representando 83,3\%), foi dada por mães. Pais representam 8,3\% (4 respostas) e avós 4,1\% ( 2 respostas). Representando $2 \%$ cada, houve a participação de uma tia e um tutor pedagógico.

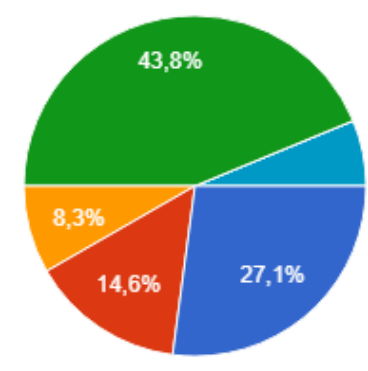

\footnotetext{
${ }^{2}$ Facebook
} 
Figura 1: relação do tipo de habitação da criança. Fonte: os autores através do Formulário Google (2018).

Os 48 participantes cuidaram ao todo de 70 crianças, considerando-se idades de 0 a 12 anos. Representando a maioria de $61,4 \%$, concentra-se as idades de um $(15,7 \%)$, dois (10\%), quatro (10\%), cinco $(14,2 \%)$ e oito anos de idade $(11,4 \%)$. Os $40 \%$ restante das crianças dividem-se nas outras faixas etárias. Como mostra a figura 1 , na maioria das respostas, a criança habita (em maior parte do tempo) em casa da área urbana, com $43 \%$ e em apartamento, com $27 \%$.

\subsection{Informações sobre a alimentação infantil}

As questões seguintes abordam o contexto da alimentação da criança. Interessante notar que apenas 4 respostas $(8,3 \%$ do total) afirmaram que a criança não participa ou observa qualquer etapa da preparação dos alimentos das suas refeições, mostrando como é uma atividade em que usualmente se procura a sua inserção. Como é apresentado na figura 2, seja por interesse da criança (31\%), pela solicitação de seu cuidador (14\%), ou ainda sem uma participação ativa, mas contando com a observação (41\%), as crianças são inseridas, de alguma forma, na preparação dos alimentos da família.
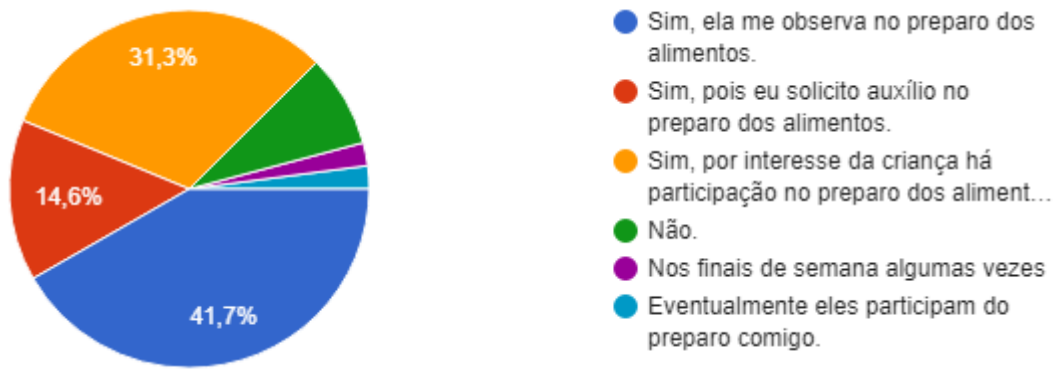

Figura 2: participação da criança no preparo das refeições. Fonte: os autores através do Formulário Google (2018).

A inserção de crianças nas práticas culinárias pode ser uma estratégia para instruir sobre os alimentos e sua preparação, sendo também um passatempo próximo a família. Aliando esta prática à atividade de cultivo apresenta-se na figura 3 um exemplo de produto que une o estes dois objetivos, o kit de jardinagem infantil para a produção de sopa, em que a criança cultiva o que consumirá.

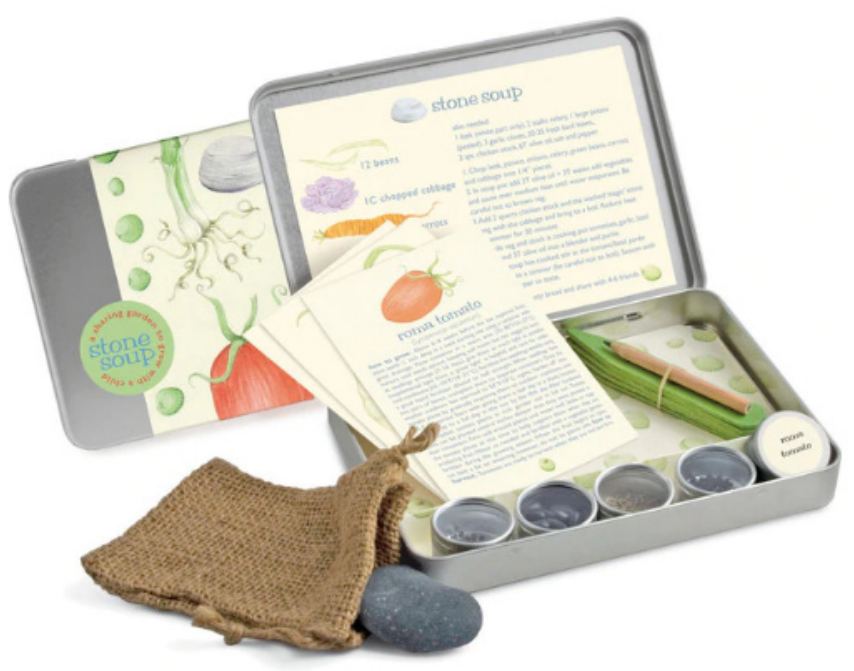

Figura 3: Kids Garden Maker Stone Soup. Fonte: www.pottingshedcreations.com/kids-garden-maker-stone-soup

Sobre os alimentos preferidos da criança, deixou-se aberto no questionário para que os respondentes listassem quantos alimentos fossem necessários para a descrição das preferências. Para o levantamento, os alimentos foram separados por grupos da forma como são comumente classificados: 
- Verduras: alimentos folhosos;

- Grãos: como feijão;

- Legumes: "vegetais cuja parte comestível não são folhas" (SBP, 2012, p. 30);

- Frutas;

- Cereais: como arroz e aveia;

- Proteínas: carnes e ovos;

- Doces;

- Massas: produtos processados de farináceos, como macarrão e pães;

- Outros: para outras respostas listadas que não se enquadram nas categorias acima.

Optou-se aqui por manter a classificação comum dos alimentos, para que o questionário fosse facilmente assimilado pelo público. No caso dos frutos, pela definição botânica "tem como função a proteção das sementes ou a sua dispersão" (SOUZA et. al., 2013, p. 188). Assim, pela descrição científica são frutos o tomate, o chuchu, a abobrinha por exemplo, mas para esse questionário, que utiliza o senso comum, não estão na classificação de frutas, mas sim como legumes pois são comumente inseridos nas refeições principais de sabor salgado.

Os legumes e as frutas foram os grupos que apresentaram maior aceitação pelas crianças, como pode ser observado no gráfico 1 . No grupo dos legumes, o tomate ( 7 respostas) e a cenoura (6 respostas) apareceram com maior frequência. Já para as frutas, a banana (com 5 respostas) foi o apontamento que mais se repetiu.

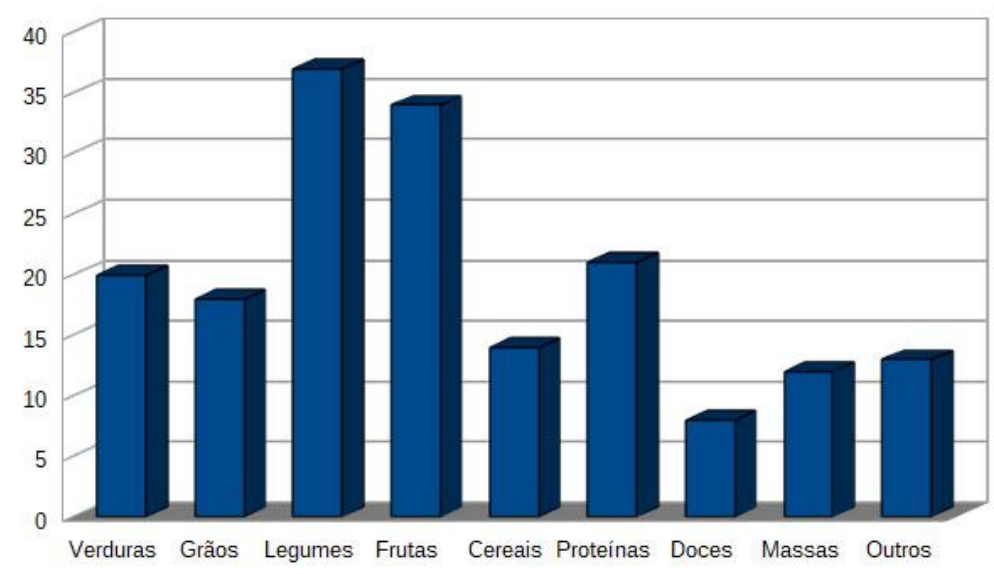

Gráfico 1: alimentos preferidos pelas crianças/quantidade de citações nas respostas. Fonte: os autores (2018).

Não houve questionamento sobre a causa da preferência pelos alimentos listados, pois deve ser lembrado que não é apenas o sabor que pode influenciar a preferência, mas também texturas, cores, quantidade de vezes que é oferecido e de quais maneiras, se as pessoas que participam da refeição com a criança também ingerem o alimento, entre tantos outros fatores (objetivos e subjetivos) que compõe as preferências pessoais por um alimento.

As proteínas aparecem representando $11,8 \%$ dos alimentos citados. O termo "carne" de forma generalizada e o ovo foram as respostas mais frequentes (6 indicações). Com representação similar se enquadram as verduras, em que o brócolis (6 indicações) foi o mais citado. O brócolis foi enquadrado aqui como verdura por ser comumente tratado como hortaliça, porém apesar de suas folhas serem comestíveis, a parte que usualmente leva-se ao prato é a flor da planta.

A alcachofra, o brócolis e a couve-flor são as três flores normalmente empregadas em alimentação. Têm valor nutritivo, e muita gente não tem ideia de que sejam flores. Muitos chamam de verdura, legume, hortaliça, mas o que se come é a parte reprodutiva dessas plantas, que são a inflorescência, os botões florais e as flores (FELIPPE, 2003, p. 23). 
Os grãos aparecem com aproximadamente $10 \%$ das respostas, tendo sido citados o milho e a ervilha, porém a maior representatividade foi o feijão com 15 apontamentos. E de forma similar nos cereais, o arroz foi citado em 13 respostas. Interessante ressaltar a baixa representatividade dos doces, com apenas 4,5\% das respostas, tendo sido apontados com o termo "doces" de forma generalizada, mas também como "mel", "bolo" e "biscoito". Atualmente há um grande esforço de órgãos como a Sociedade Brasileira de Pediatria (SBP) para evitar o consumo do açúcar antes dos dois anos de vida da criança.

[...] chás, bebidas açucaradas e outros alimentos, como chocolate e refrigerantes, podem ter significados culturais muito enraizados e gerar forte apelo por parte dos familiares, demandando argumentos fortes e esclarecidos para convencer os pais de que deverão banir estes alimentos nos primeiros anos de vida da criança (SBP, 2012, p. 25).

Já as massas representam 6,7\% contendo os termos "massas", "macarrão", "pão" e "lasanha". Juntos os termos massas e macarrão são citados em 10 respostas. Lembra-se que apesar de atualmente haver uma grande divulgação de dietas de baixo consumo de carboidratos ou de glúten, há por outro lado, diversos estudos que indicam a necessidade de se inserir o glúten na introdução alimentar para aproveitar uma janela imunológica e assim evitar futuras doenças. Assim, é comum que pediatras indiquem a introdução do glúten através de massas a partir do $6^{\circ}$ mês de vida.

A ESPGHAN Commitee on Nutrition (2008), considera prudente evitar a introdução tanto prévia (antes dos quatro meses) quanto tardia (depois dos sete meses) de glúten, apelando à sua introdução gradual durante a amamentação, o que reduzirá o risco de doença celíaca, diabetes mellitus tipo 1 e alergia ao glúten (SILVA e AGUIAR, 2011, p. 1039).

Já em relação aos alimentos que são mais comumente rejeitados pelas crianças (gráfico 2) os vegetais são predominantemente apontados, os legumes representam aproximadamente $35 \%$ (25 respostas) e as verduras com $28 \%$ (20 respostas). O termo "legumes" de forma generalizada, assim como a cebola, foram os itens mais apontados, com 4 respostas cada. Já para o grupo das verduras, os termos genéricos que se repetiram foram "folhas", "salada" e "verduras", com 3 respostas cada. E o alimento mais apontado por rejeição foi a alface, com 4 respostas.

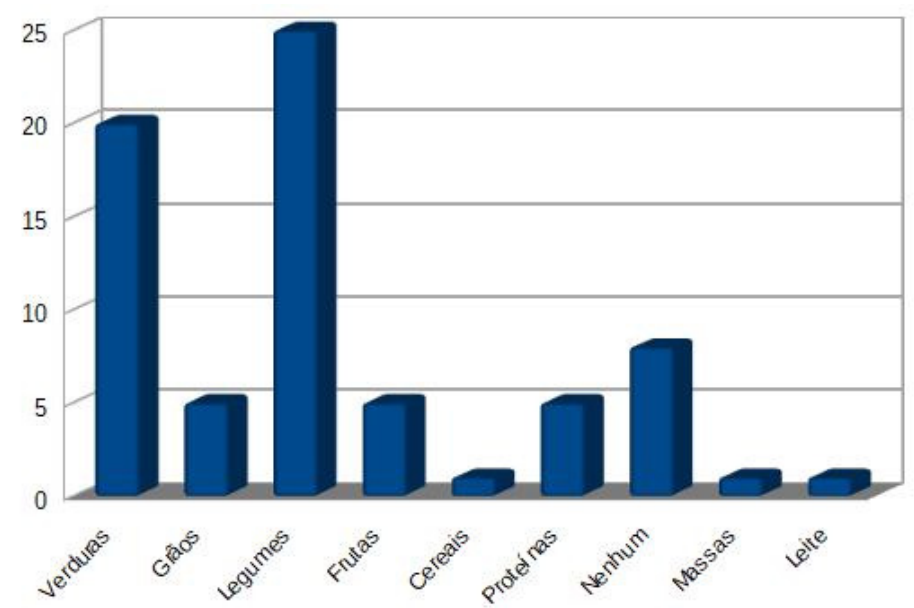

Gráfico 2: alimentos mais rejeitados pelas crianças. Fonte: os autores (2018).

O gráfico 3 apresenta os locais de aquisição dos alimentos que são oferecidos à(s) criança(s). Observa-se que os hiper e supermercados são a forma mais comum de compra de alimento (42 respostas), seguido pelo hortifrúti (23 respostas). Nesta questão a soma das respostas ultrapassa o total 
de participantes pois ficou em aberto para que se marcasse quantas respostas fossem necessárias para contextualizar a rotina de alimentação, uma vez que as famílias podem utilizar mais de um tipo de estabelecimento comercial para abastecimento do lar.

Com representação similar apresentam-se a feira de bairro (18 respostas), o cultivo na própria residência (17 respostas), lojas e pequenos mercados e o açougue (14 respostas cada). Todas as formas de aquisição se mostram complementares a ida ao supermercado, afinal, ao contrário dos outros estabelecimentos comerciais, é um local onde há grande disponibilidade de produtos e não apenas os alimentícios, como o restante das opções. Isto sugere que a praticidade ainda é fator fundamental de escolha dentro do estilo de vida urbano.

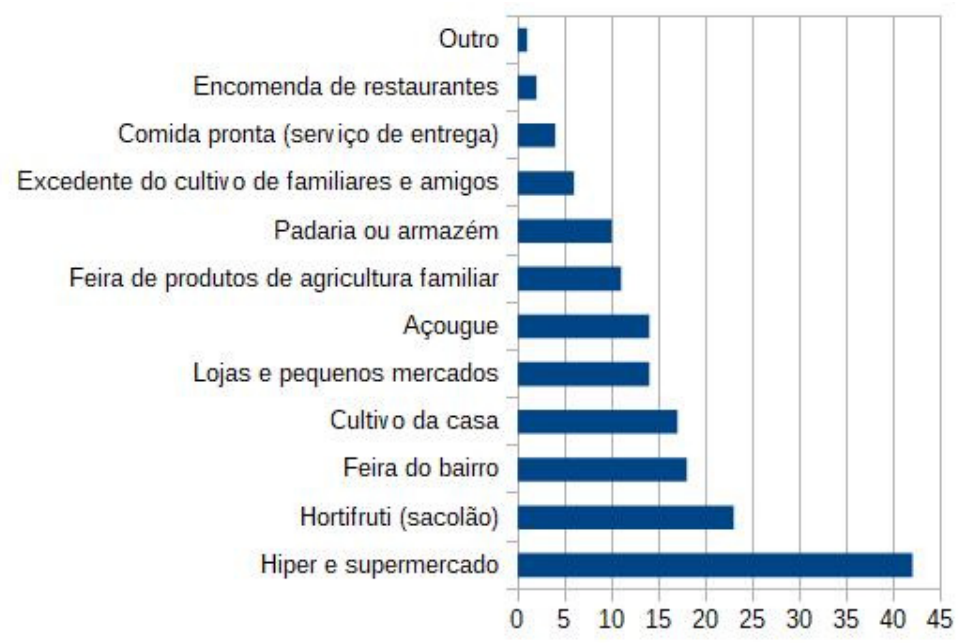

Gráfico 3: locais de aquisição dos alimentos oferecidos à(s) criança(s). Fonte: os autores (2018).

Independente da forma de aquisição do alimento a SBP sugere como uma orientação geral para que a conduta alimentar infantil seja saudável e a formação do hábito adequada, "envolver a criança nas tarefas que incluam as compras e a preparação das refeições, como participar da escolha do alimento, da sua compra no mercado ou feira e da elaboração dos pratos que não apresentem riscos de acidentes ao manuseio" (SBP, 2012, p. 45).

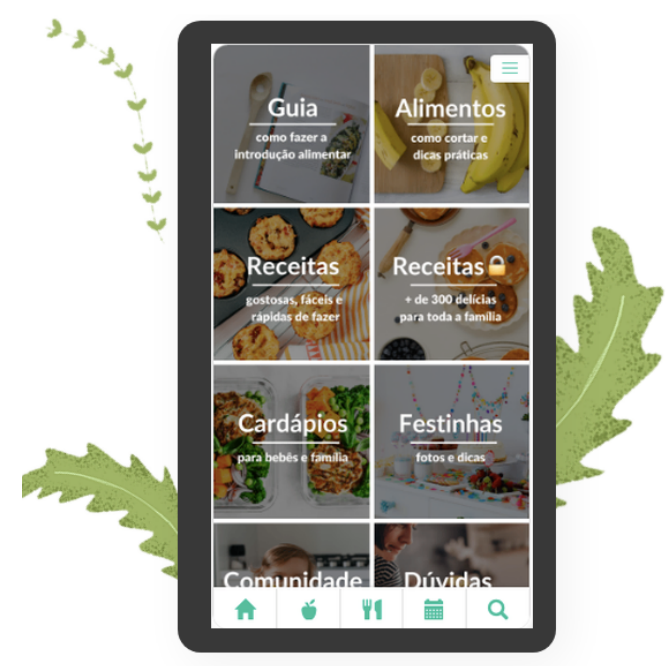

Figura 4: Interface gráfica de aplicativo para introdução alimentar. Fonte: www.blwbrasilapp.com.br/

Já em relação às dificuldades encontradas para a seleção e preparo da comida para crianças, o item mais apontado, com $25 \%$ das respostas, foi a dificuldade em variar os alimentos oferecidos nas refeições. Os apontamentos seguintes referem-se a conseguir encontrar produtos específicos e a falta 
de tempo para preparo (ambos com 12\% cada). Neste item, as famílias conseguem ampla sugestão de cardápios disponíveis na internet e em aplicativos específicos. Aqui o designer tem o desafio de criar interfaces para que os usuários tenham acesso de forma adequada à informação. A figura 4 mostra a disposição das informações em aplicativo voltado para a introdução alimentar, apesar de não lidar diretamente com o cultivo ou com a alimentação, o design da informação trará resultados eficientes para os usuários também nestes contextos.

\subsection{0 cultivo de plantas}

Sobre o cultivo de plantas nas residências, a maioria dos participantes da pesquisa o praticam de alguma forma. Seja com plantas alimentícias em maior parte $(64,6 \%)$, como também para outro fim $(10,4 \%)$. Em menor parte, $4 \%$, dizem cultivar plantas em outros espaços que não o da residência, e $20 \%$ afirmam não praticar qualquer atividade de cultivo (figura 5).

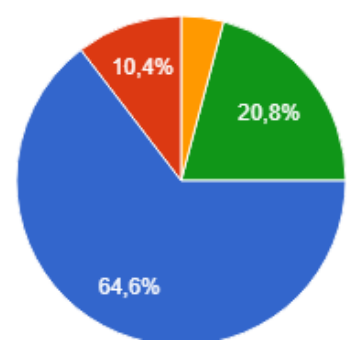

Sim

Não, cultivo plantas para outro fim (ornamental, medicinal, religioso, etc).

Não, cultivo plantas em outro local (sítio por exemplo)

Não cultivo plantas em casa

Figura 5: cultivo de plantas alimentícias na residência. Fonte: os autores através do Formulário Google (2018).

Quando questionados sobre quais as plantas são mais cultivadas nas residências, foram citados uma diversidade de vegetais, 187 diferentes tipos, que foram agrupados por suas características alimentares ou ornamentais, como mostra o gráfico 4 .

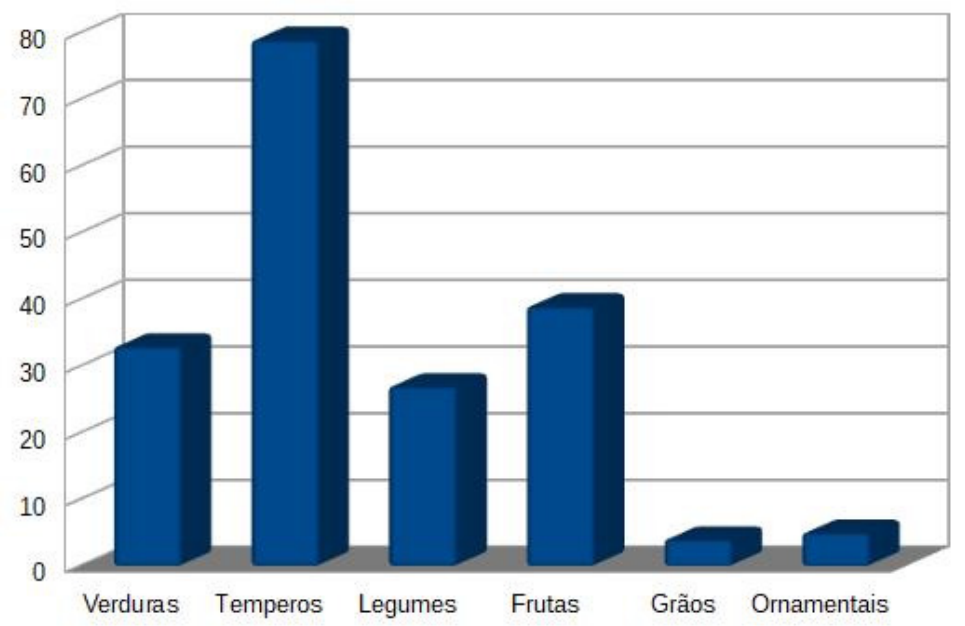

Gráfico 4: grupos de plantas cultivadas nas residências. Fonte: os autores (2018).

Ressalta-se primeiramente a adesão ao cultivo de temperos, grupo que ocupa $42 \%$ das plantas que são cultivadas nas residências (com 79 apontamentos). Neste grupo, os vegetais mais citados foram a cebolinha (14 respostas), a salsa (12 respostas) e o manjericão (11 respostas).

O segundo maior grupo foi o das frutas, com $20 \%$ das plantas. Ao contrário dos temperos, as respostas aqui foram diversificadas. Enquanto os temperos apresentaram 13 diferentes plantas citadas, foram apresentadas 23 diferentes tipos de frutas cultivadas. As respostas que mais se repetiram foram o cultivo do limão (5 respostas), da laranja (4 respostas), da acerola e do morango (com 3 respostas cada). 
Com $17 \%$ das respostas, se encontra o grupo das verduras, em que a alface (com 9 respostas) e a couve ( 8 respostas) foram as mais cultivadas. Já o grupo dos legumes representa $14 \%$, com ênfase no cultivo do tomate (6 respostas). Com $2 \%$ cada, se encontram tanto o grupo das plantas ornamentais como dos grãos sem plantas predominantes nas respostas.

Há uma série de dispositivos disponíveis no mercado para a inserção de crianças nas atividades de cultivo. Usualmente utilizam-se plantas de crescimento rápido, para que a criança acompanhe seu desenvolvimento, além de ferramentas e suportes em dimensões reduzidas para se adequar aos usuários. Além disso podem ser inseridas outras funções, como o "jardim no pacote" da empresa Potting Shed Creations que traz a oportunidade de desenhar no rótulo (figura 6).
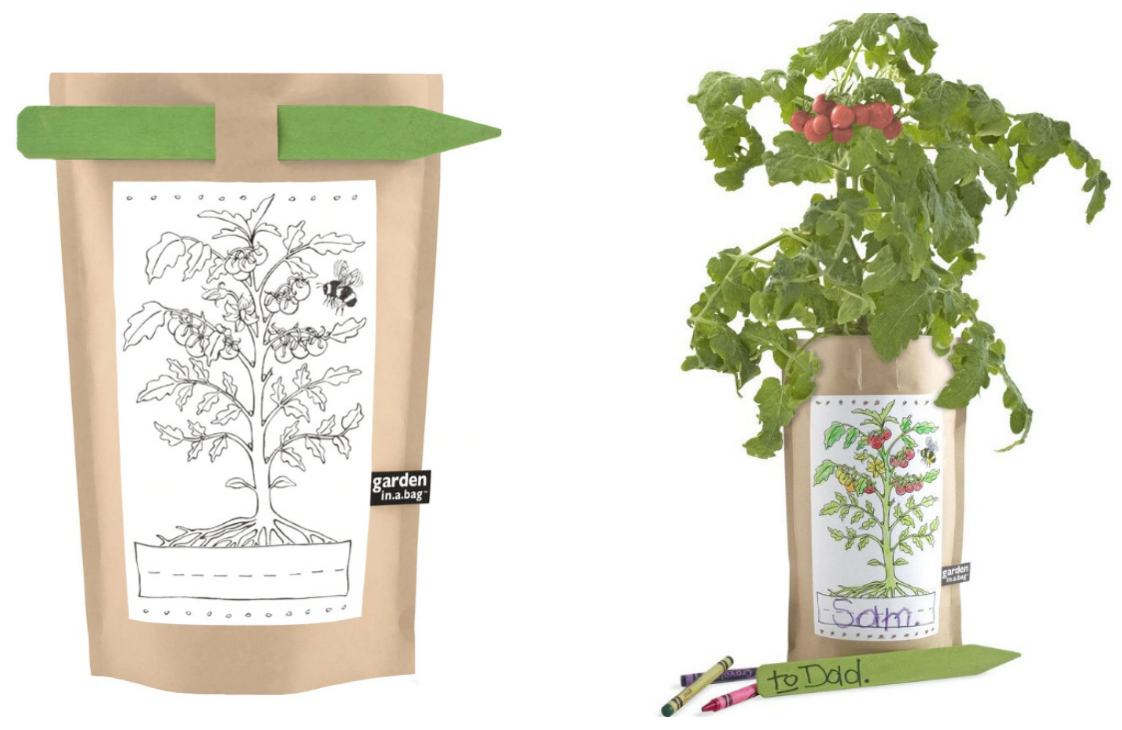

Figura 6: Kids Garden-in-a-bag Tomato. Fonte: www.pottingshedcreations.com/kids-garden-in-a-bag-tomato/

Em relação a localização das plantas e das atividades de cultivo nas residências, como mostra o gráfico 5, as áreas externas são as mais utilizadas. O quintal se mostra como a área mais escolhida para o cultivo, tendo sido citado em $43 \%$ das respostas. Abaixo, segue o jardim e a varanda apresentando resultados próximos, com $15 \%$ e $13 \%$ das respostas, seguido pelo peitoril de janelas, com $9 \%$. Com quantidade similar, foram citadas a cozinha e a cobertura (com 5\% cada) e a área de serviço (3\%). Com apenas 1 resposta (representando 1,9\%) foi apontada a sala como espaço de cultivo. Não foram apontadas as áreas de quarto, copa e banheiro.

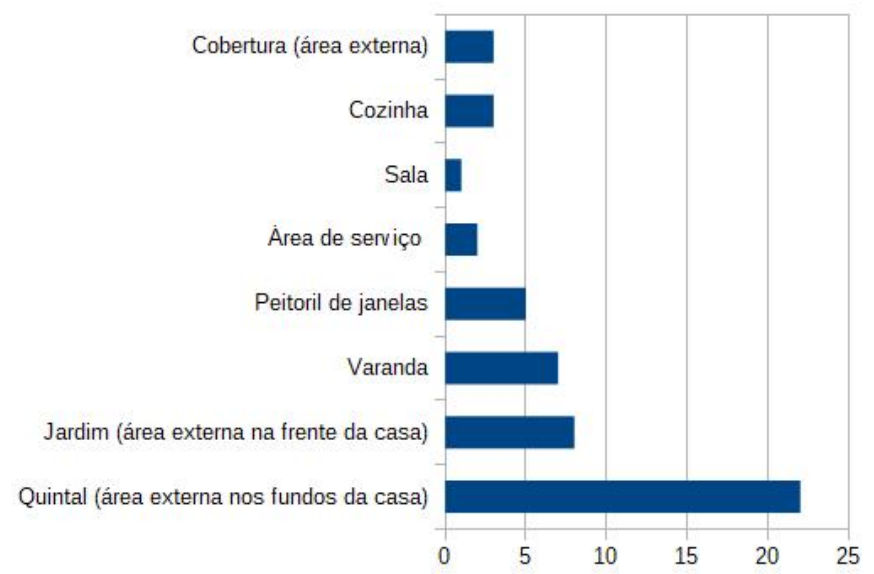

Gráfico 5: distribuição das plantas nas residências. Fonte: os autores (2018).

Apesar de não haver apontamentos para as áreas mais internas da casa, há diversos trabalhos de decoradores e designers de ambientes que inserem as plantas nos ambientes de quarto, banheiro e copa. Há ainda propostas como o do Studio Patrick Nadeau que desenvolve projetos inspirados em 
plantas onde combina arquitetura de interiores, design de objetos e cenografia. No projeto do banheiro Green Waters as plantas foram usadas para auxiliar na reciclagem da água (figura 7).

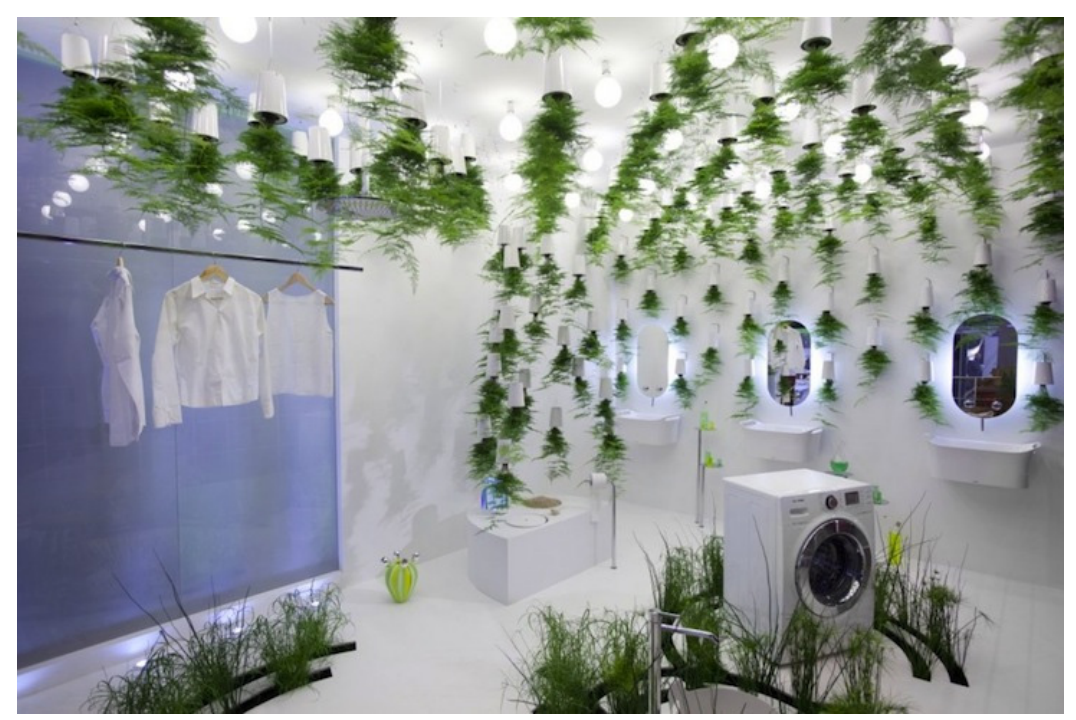

Figura 7: Green Waters de Patrick Nadeau. Fonte: inhabitat.com/patrick-nadeaus-green-waters-bathroom-useshanging-plants-to-treat-greywater/

Para entender melhor o tipo de aproximação das crianças com as atividades cultivo, foi questionado se nas áreas de creche ou escola, são oferecidas atividades com plantas, como a horta por exemplo. A maioria das respostas $(60,4 \%)$, indica que as instituições de ensino se preocupam em oferecer algum tipo de contato com as atividades de cultivo de plantas, em contraponto com $20,8 \%$ das respostas que indicam não haver este tipo de atividade. O restante dos participantes $(18,8 \%$ disseram que as crianças ainda não frequentam creche ou escola (figura 8).
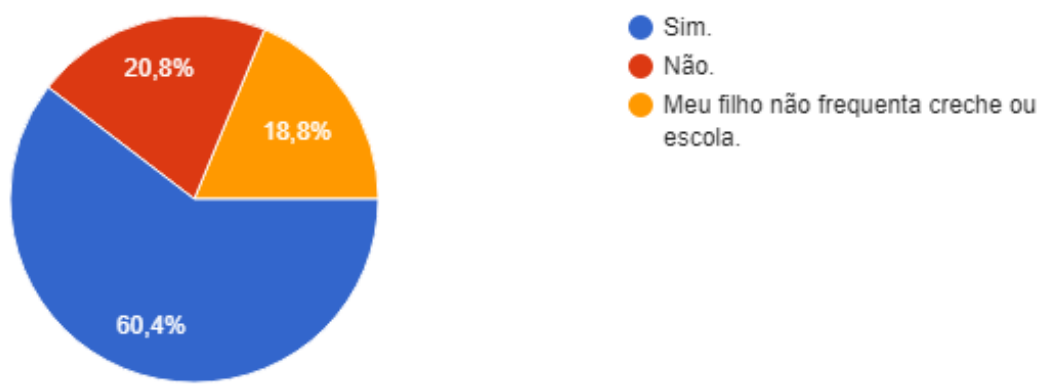
escola.

Figura 8: atividades de cultivo na creche/escola. Fonte: os autores através do Formulário Google (2018).

Também foi questionado se a criança participa das atividades de cultivo em sua própria residência, e de quais atividades especificamente (gráfico 6).

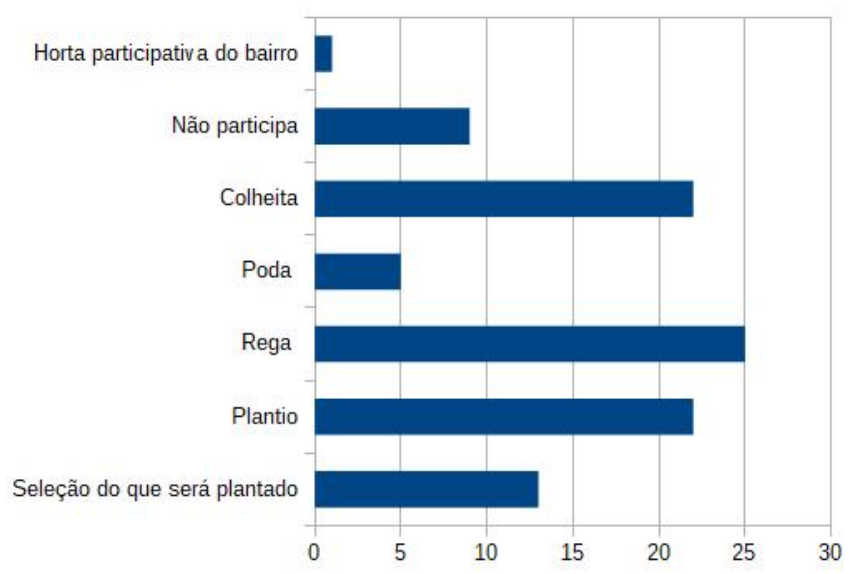


Gráfico 6: participação da(s) criança(s) nas atividades de cultivo. Fonte: os autores (2018).

De acordo com as respostas, a maior inserção das crianças está nas atividades de rega (25 respostas), plantio e colheita (com 22 respostas cada). As crianças também participam da seleção de qual planta será cultivada na residência (13 respostas) e na poda (5 respostas). Com 9 respostas indicam que a criança não participa de qualquer tipo de atividade de cultivo e apenas uma resposta especificou a participação em hortas coletivas do próprio bairro.

O gráfico 7 apresenta os resultados referentes ao tipo de influência que o cultivo de plantas exerce na vida da criança que o pratica. A resposta mais apontada se refere ao contato da criança com a natureza (com 33 respostas) e logo depois ao conhecimento que esta adquire sobre plantas e alimentos (29 respostas). Com valores próximos, foram citados o fato das atividades de cultivo despertarem na criança a preocupação com meio ambiente (23 respostas), o fato de promover uma atividade exercida em família (20 respostas), assim como promover uma maior aceitação de diferentes tipos de alimentos (19 respostas). Uma resposta se refere a aquisição de compromisso, aqui entendido como o compromisso com a rotina de cuidados com o vegetal, logo a aquisição de uma responsabilidade, e por fim, 5 respostas disseram que o cultivo não apresenta nenhuma influência na vida da criança.

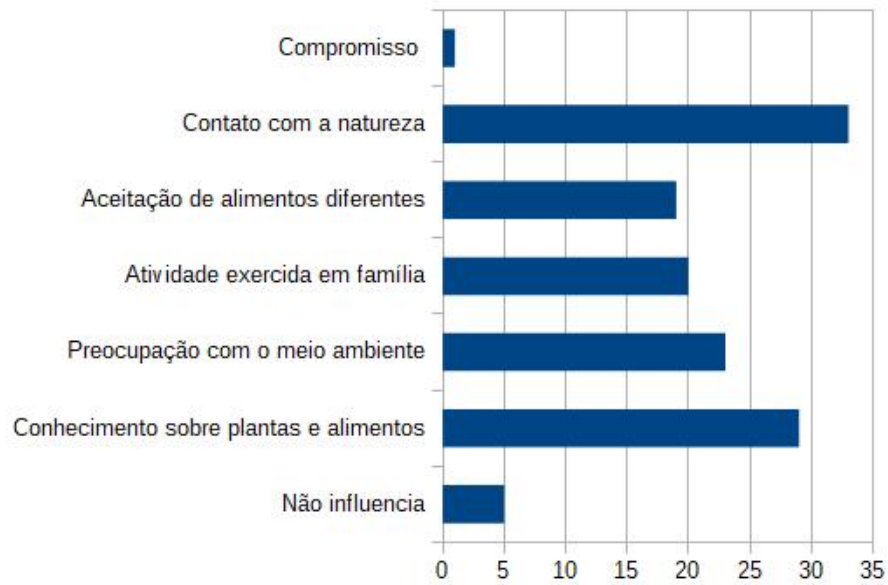

Gráfico 7: tipos de influência do cultivo na vida da(s) criança(s). Fonte: os autores (2018).

O gráfico 8 apresenta a relação das maiores dificuldades encontradas para se cultivar plantas nas residências. As principais respostas são referentes a falta de espaço (22 respostas), falta de tempo (19 respostas), falta de conhecimento sobre o cultivo de plantas (18 respostas) e incidência de pragas (10 respostas). Foram citadas, em menor número, também questões como a dificuldade em adquirir sementes ou mudas de plantas específicas, a sujeira gerada pela atividade, o preço dos insumos e o trabalho ocasionado pela manutenção das plantas.

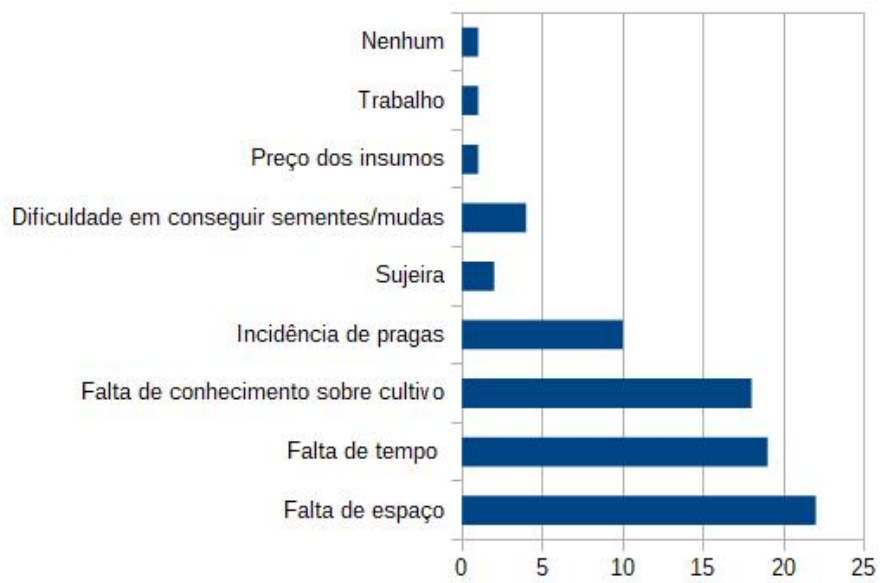

Gráfico 8: principais dificuldades encontradas no cultivo doméstico de plantas. Fonte: os autores (2018). 
Por fim, o gráfico 9 mostra o resultado do questionamento sobre os principais benefícios em se cultivar plantas em casa. A maioria dos apontamentos referem-se a qualidade dos alimentos ingeridos, sendo: 25 respostas indicaram como benefício a possibilidade de se consumir alimentos orgânicos, 6 respostas para alimentos frescos, 5 para alimentos saudáveis e 4 indicaram a importância em ter segurança sobre a procedência do alimento. Exercer uma atividade terapêutica também se mostrou fator importante (6 respostas), assim como proporcionar praticidade aos que cultivam ( 5 respostas) e também o contato com a natureza (4 respostas). Com menor representatividade foram citados o conhecimento e a qualidade dos alimentos, estar em um ambiente saudável com uma atividade exercida em família, economia, diversidade e decoração.

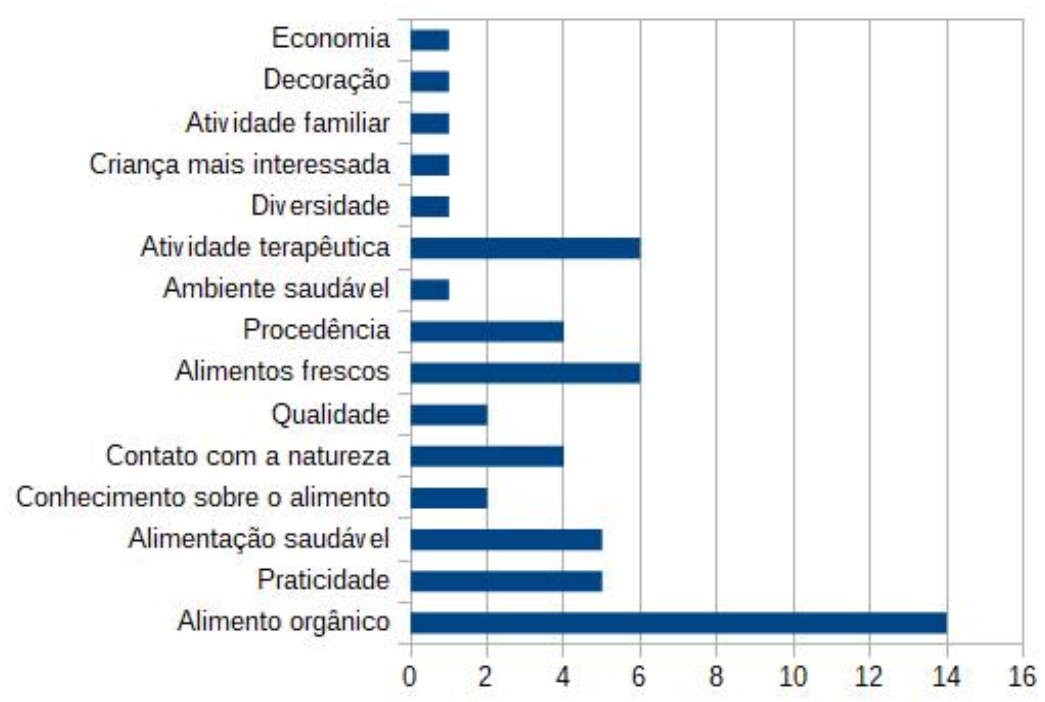

Gráfico 9: principais benefícios em se cultivar plantas na residência. Fonte: os autores (2018).

\section{Conclusões: cultivo para a qualidade de vida mas sem soberania alimentar}

O questionário auxilia a embasar algumas questões sobre o processo do cultivo nas residências das áreas urbanas. Há sim uma preocupação no cultivo de alimentos mesmo que estes não sejam a principal fonte das refeições da família. Aspectos subjetivos como o contato com a natureza ou terapia se mostram tão importantes quanto produzir o próprio alimento. Logo, para projetar para este universo, o designer deve compreender que as questões subjetivas relacionadas a atividade, como o prazer, são tão ou mais importantes do que essencialmente a eficiência do cultivo.

A grande presença de temperos mostra que o cultivo doméstico, em especial nas áreas urbanas, está longe de ser uma atividade que trará a soberania alimentar a este grupo. O conceito de soberania alimentar é apresentado pelo CONSEA $(2016$, p. 6) que diz que "cada país tem o direito de definir suas próprias políticas e estratégias sustentáveis de produção, distribuição e consumo de alimentos que garantam o direito à alimentação para toda população (soberania alimentar), respeitando as múltiplas características culturais dos povos".

Se a lei garante ao país o poder decisório sobre cultivo e alimentação, o mesmo não pode ser dito de seus indivíduos. Os modelos de habitação urbanos muitas vezes não permitem o cultivo do que se quer, mas daquilo que é possível com espaços reduzidos, sem contato com a terra e muitas vezes contando com pouca luminosidade e áreas fechadas. Os hábitos de vida contemporâneos associados ao ambiente urbano apartam os indivíduos dos conhecimentos práticos sobre cultivo e sobre as espécies locais. Lembrando que a falta de espaço, tempo e conhecimento foram as principais dificuldades para se cultivar, como apontou o gráfico 8. Uma alimentação sem agrotóxicos é uma das principais justificativas para o cultivo de plantas alimentícias, mas apesar da importância para as pessoas, ainda assim os alimentos orgânicos têm preços altos e são de difícil acesso. 
Se por um lado há uma série de obstáculos que dificultam o acesso a alimentos de qualidade, em paralelo surgem iniciativas, principalmente pela agroecologia, com demandas de assegurar a soberania alimentar dos indivíduos.

Iniciativas "agroecológicas", como o resgate e a manutenção de sementes varietais pelas famílias agricultoras, a conservação de recursos naturais, a produção de alimentos limpos e a articulação de novas redes de distribuição e consumo de alimentos, são condições indispensáveis para garantir o acesso a alimentos de qualidade para todos. E, como já vimos, acesso é um problema central quando o tema é Soberania Alimentar (MEIRELLES, 2004, p. 12).

Em relação ao acesso a alimentos de qualidade, as redes sociais e a interatividade da internet são instrumentos comumente usados entre pessoas para a troca de informações. Com isso produtores orgânicos conseguem reduzir os intermediários e vender diretamente ao consumidor utilizando aplicativos para smartphone. Sites como o Sementeria ${ }^{3}$ proporcionam a possibilidade de doar ou trocar sementes de espécies nativas, difíceis de encontrar no mercado. Neste contexto, mais uma vez ressaltase a importância do design de interface e o design da informação, que são essenciais para que o consumidor tenha acesso a uma ampla gama de possibilidades dentro da atividade de cultivo e alimentação.

Se a soberania alimentar ainda não pode ser alcançada por todos, tanto em termos de cultivo como de acesso, as atividades de plantio de alimentos demonstram ainda funções importantes. Os dados mostram que os alimentos mais rejeitados pelas crianças são verduras e legumes, não significando que sejam alimentos banidos das refeições das famílias. Pelo contrário, justamente por serem oferecidos às crianças, que podem então, ser rejeitados. Esta justificativa pode ser embasada pelo gráfico 1, que mostram que os legumes também são, ao mesmo tempo, os alimentos preferidos pelas crianças.

É interessante citar o curioso papel das verduras e dos temperos tanto no cultivo como na alimentação, quando relacionamos as questões de preferência e rejeição. Os temperos são tipo de planta mais cultivado nas residências, mesmo não tendo sido citados por qualquer respondente como um alimento preferido ou rejeitado. Supõe-se aqui, que são plantas que não são consideradas alimentos por si só, mas complementos para dar sabor aos alimentos.

Excluindo-se o grupo dos temperos (por não terem sido citados nas preferências ou rejeições), as verduras ficam em segundo lugar como grupo mais cultivado, mesmo sendo o segundo grupo mais rejeitado pelas crianças. Em particular a alface, que foi item das verduras mais cultivado e também o item apontado como mais rejeitado.

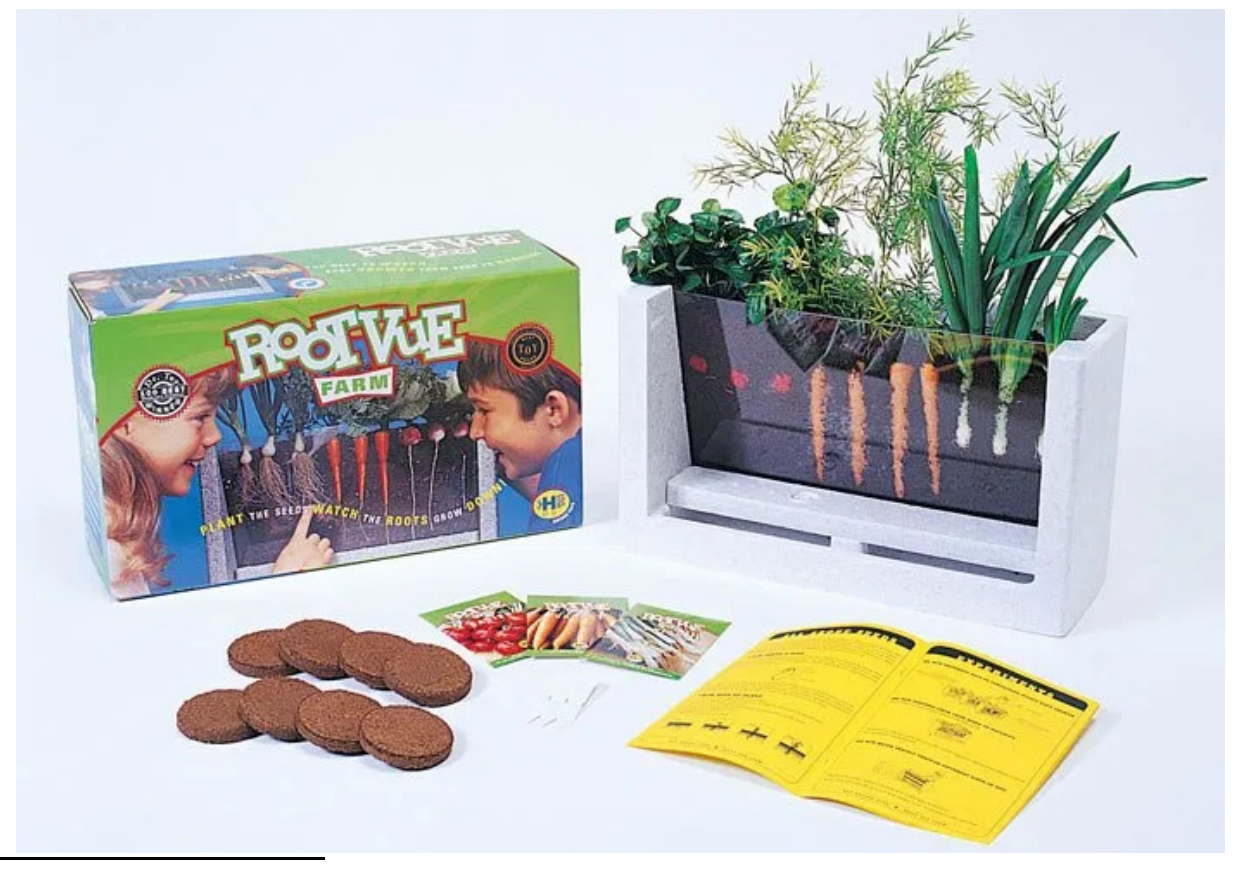

\footnotetext{
${ }^{3}$ www.sementeria.com.br
} 
Figura 9: Root-Vue Farm Kit. Fonte:https://www.hspnaturetoys.com/product/root-vue-farm/

Se inserir a crianças nas atividades de cultivo pode ser uma estratégia para auxiliar na ingestão de alimentos naturais, muitas vezes rejeitados, o design pode auxiliar a inserir outros atrativos no cultivo, e o contato prolongado da criança com os vegetais pode trazer a curiosidade em se provar o alimento. Um exemplo de produto que alia outros atrativos à atividade de cultivo é o premiado Root Vue Farm Kit da empresa HSP Nature Toys (figura 9), um jogo que permite que a criança acompanhe o crescimento do vegetal visualizando suas raízes.

As áreas abertas das residências são as mais usadas para cultivar, interessante e ponto em potencial para o design é criar alternativas que insiram a horta no interior das casas de forma a manter os hábitos de cultivo e não apresentar um produto que substitua o indivíduo nesta atividade.

Os sistemas internos de cultivo que gerenciam a rega e iluminação de plantas já estão disponíveis no Brasil, mas o hábito de lidar diretamente com a planta e com a terra se mostra como uma atividade base para aqueles que a praticam. Isso é reforçado pelo dado apresentado no gráfico 8 , que mostra que apesar de o espaço ter sido citado como principal dificuldade para o cultivo, a sujeira foi pouco apontada, mostrando que não é considerada um problema pelos praticantes.

O cultivo de plantas é uma atividade em que se busca a aproximação das crianças, mas não apenas por questões alimentícias, leva-se em conta todos os aspectos subjetivos tratados anteriormente. Uma das justificativas é a maior representatividade de crianças que frequentam creches ou escolas com hortas, assim como a preocupação dos cuidadores que responderam ao questionário em inserir a criança nos processos de preparo dos alimentos.

Nas influências que as atividades de cultivo exercem em crianças, não são apontados o acesso a alimentos específicos ou a uma alimentação de qualidade e sem agrotóxico, mas sim o contato com a natureza, o conhecimento sobre alimentos e plantas e a preocupação com o cuidado com o meio ambiente, em maior quantidade.

Se atualmente os hábitos urbanos separam o indivíduo dos elementos naturais, como as plantas, parece que os participantes da pesquisa entendem que a simples aproximação com o reino vegetal é um fator importante para que crianças iniciem uma conscientização ambiental. Além do entendimento de que a infância será melhor se houver contato com a natureza, assim para se estabelecer uma vivência, a criança é inserida nas atividades de cultivo.

Conclui-se então que o cultivo de plantas alimentícias não é uma necessidade puramente alimentar, muito pelo contrário. Todos os outros aspectos de terapia, conscientização ambiental, contato com a natureza, entre outros, se mostram como as principais consequências das atividades de cultivo doméstico que devem ser analisadas pelo design.

\section{Conviviality with plants and good nutrition: the role of design in cultivation activities}

\section{Abstract:}

The present paper approaches the interaction of children who live in urban residences in gardening activities as a way to insert healthy foods in their diet. For this research presents it as applied a questionnaire with topics on the importance of cultivation and its forms in the urban context, drawing a parallel on the alternatives presented from the design point of view. As a result, it was understood that the cultivation of plants in urban environments faces a series of difficulties but resists, not as a way of bringing food sovereignty to a family, but as subjective factors related to a therapeutic, recreational and environmental awareness activity. Thus, bringing to the designer the challenge of inserting intangible factors into their projects that are as relevant as the productive efficiency of a domestic garden. 


\section{Referências bibliográficas}

CONSEA. Conselho Nacional de Segurança Alimentar e Nutricional. Lei de segurança alimentar e nutricional. Conceitos: Lei $n^{\circ} 11.346$, de 15 de setembro de 2006. Disponível em:

<http://www.mds.gov.br/webarquivos/publicacao/seguranca_alimentar/cartilha_lei_seguranca_alimen tar.pdf>. Acesso em: 07/02/2019.

FELIPPE, Gil Martins. Entre o jardim e a horta: as flores que vão para a mesa. São Paulo: Editora Senac São Paulo, 2003.

GIL, Antônio Carlos. Métodos e técnicas de pesquisa social. Atlas. São Paulo: 2008.

MEIRELLES, Laércio. Soberania Alimentar, agroecologia e mercados locais. Agriculturas - v. 1 - no 0 - setembro de 2004. Disponível em: <http://orgprints.org/21244/1/Meirelles_soberania.pdf>. Acesso em: 07/02/2019.

MUGGIRI, Martina. Iniciativas de valorização da agrobiodiversidade e do território na perspectiva do design sistêmico: Brasil e Itália. In.: KRUCKEN, L et. al. Territórios criativos para a valorização da cultura gastronômica e artesanal. Belo Horizonte: editora Atafona, 2017. Disponível em: <shorturl.at/mwKQY>. Acesso em: 10/10/2018.

PINTO, Laura de Souza Cota Carvalho Silva; Design, alimento e negócio: o caso De-Lá, um empório em busca da valorização do território brasileiro. In: OLIVEIRA, Alfredo Jefferson de; FRANZATO, Carlo; GAUDIO, Chiara Del. Ecovisões projetuais: pesquisas em design e sustentabilidade no Brasil. São Paulo: Blucher, 2017. Disponível em: <http://pdf.blucher.com.br.s3-sa-east1.amazonaws.com/openaccess/9788580392661/30.pdf>. Acesso em: 10/10/2018.

SBP. Sociedade Brasileira de Pediatria. Manual de orientação para a alimentação do lactente, do pré-escolar, do escolar, do adolescente e na escola. Departamento de Nutrologia, $3^{a}$. ed. SBP. Rio de Janeiro: 2012. Disponível em:

<http://www.sbp.com.br/fileadmin/user_upload/publicacoes/14617a-pdmanualnutrologiaalimentacao.pdf>. Acesso em: 15/08/2018.

SILVA, Ana Isabel; AGUIAR, Hélder Gabriel. Diversificação alimentar no primeiro ano de vida. Acta Médica Portuguesa, 2011; 24(S4): 1035-1040. Disponível em:

<http://www.feingold.org/Research/PDFstudies/Silva2011-open.pdf>. Acesso em: 14/08/2018.

SOUZA, Vinícius Castro; FLORES, Thiago Bevilacqua; LORENZI, Harri. Introdução à botânica: morfologia. São Paulo: Instituto Plantarum de Estudos da Flora, 2013. 